\title{
ESTUDOS SOBRE INICIAÇÃO CIENTÍFICA NO BRASIL: UMA REVISÃO
}

\author{
LUCIANA MASSI \\ Doutoranda do Programa de Pós-Graduação Interunidades em Ensino de Ciências, da \\ Universidade de São Paulo \\ lu_massi@yahoo.com.br
}

\section{SALETE LINHARES QUEIROZ}

Professora do Instituto de Química de São Carlos, da Universidade de São Paulo

salete@iqsc.usp.br

\section{RESUMO}

O artigo apresenta uma revisão de estudos publicados sobre Iniciação Científica no Brasil, tomando por base levantamento das publicações acadêmicas sobre o tema, que abrangeu o período de 1983 ao primeiro semestre de 2007. Na literatura examinada foram encontrados elementos valiosos para a compreensão do estágio em que se encontram importantes questões pertinentes à Iniciação Científica. A emergência do campo de estudo e suas principais abordagens estão aqui descritas.

INICIAÇÃO CIENTIIFICA - REVISÃO DA LITERATURA - ENSINO SUPERIOR - QUÍMICA

\section{ABSTRACT}

STUDIES ON UNDERGRADUATE RESEARCH IN BRAZIL: A REVIEW. This article presents a review of published studies on undergraduate scientific research in Brazil, based on a survey of academic publications related to this theme. Covering the period from 1983 to the first half of 2007, the examined literature offers useful information for understanding the current stage of undergraduate research. The results show an emerging field of study and point out how it has been academically approached.

UNDERGRADUATE SCIENTIFIC RESEARCH - LITERATURE REVIEW - HIGHER EDUCATION CHEMISTRY

Texto proveniente de dissertação de mestrado (Massi, 2008), sob orientação da Profa. Dra. Salete Linhares Queiroz, cuja pesquisa obteve apoio nanceiro da Fundação de Amparo à Pesquisa do Estado de São Paulo - Fapesp. 
Definições de iniciação, como a apresentada a seguir, fornecem pistas sobre a aplicação desse conceito no contexto científico e nos permitem considerar a Iniciação Científica - IC - como um processo no qual é fornecido o conjunto de conhecimentos indispensáveis para iniciar o jovem nos ritos, técnicas e tradições da ciência: "Ato de dar ou receber os primeiros elementos de uma prática ou os rudimentos relativos a uma área do saber. Ex.: i. científica" (Houaiss, 2007).

Nessa perspectiva, o conceito de IC foi construído no interior das universidades brasileiras como uma atividade realizada durante a graduação, na qual o aluno é iniciado no "jogo" da ciência e vivencia experiências vinculadas a um projeto de pesquisa, elaborado e desenvolvido sob a orientação de um docente (Simão et al., 1996).

Surpreendentemente, apesar da ampla disseminação das atividades de IC no Brasil, não há muitos estudos a esse respeito. Este trabalho busca fazer uma síntese integrativa sobre o tema da IC, com base na análise das dissertações e teses defendidas nos programas de pós-graduação no país e em artigos publicados a esse respeito. Para tanto, realizamos um levantamento bibliográfico que abarcou o exame dos trabalhos publicados sobre o tema, de 1983 ao primeiro semestre de 2007, nas seguintes bases de dados: Banco de Teses da Capes, Biblioteca Digital de Teses e Dissertações, Portal Periódicos Capes.

A seguir, fazemos um breve histórico sobre a instituição e o funcionamento da IC nas universidades brasileiras e apontamos algumas características das pesquisas cujo campo investigativo é a IC.

\section{INSTITUIÇÃO E FUNCIONAMENTO DA INICIAÇÃO CIENTÍFICA NAS UNIVERSIDADES BRASILEIRAS}

O reconhecimento da importância estratégica da ciência e a necessidade de institucionalizar as ações de incentivo e fomento à pesquisa levaram o Brasil a criar, em 1951, o Conselho Nacional de Desenvolvimento Científico e Tecnológico - CNPq. Assim, teve início o financiamento da atividade de IC, por meio da concessão de bolsas anuais de fomento à pesquisa na graduação, "embora já existisse na prática e de forma incipiente a atividade de pesquisa com alunos ajudantes nos anos 40 e 50" (Bariani, 1998). O CNPq, no entanto, não é o único órgão de fomento à pesquisa na graduação. As Fundações de 
Amparo à Pesquisa - FAPs -, presentes em alguns estados do Brasil, também financiam a IC.

O financiamento das atividades de IC encontrou respaldo na Lei da Reforma Universitária de 1968 (Art. $2^{\circ}$, da Lei n. 5.540, de 28/I I/I 968), que determinou o princípio da "indissociabilidade ensino-pesquisa" como "norma disciplinadora do ensino superior" (Maldonado, 1998). Mais tarde essa associação foi incorporada na Constituição de 1988 e, consequentemente, na nova Lei de Diretrizes e Bases da Educação Nacional (Lei n. 9.394, de 20/I 2/1996).

Segundo Bazin (1983, p.82), "para criar o Programa de Iniciação Científica, as universidades brasileiras foram buscar inspiração nos países que já tinham uma atividade científica institucionalizada: Estados Unidos e França". Nos EUA, o programa Research and Development envolve os alunos de ciência e engenharia na produção de uma tese relacionada às atividades em curso no departamento no último ano de graduação. Na França, a atividade, menos formal, consiste em estágio em um laboratório universitário ou industrial, a partir do qual o estudante apresenta um relatório final.

Dados relativos às bolsas de IC concedidas pelo CNPq (Brasil, 2007a) demonstram um aumento acentuado na quantidade de bolsas distribuídas de 1963 a 2005. Atualmente, o número de bolsas de IC é consideravelmente superior ao número de bolsas com outras finalidades concedidas pelo $\mathrm{CNPq}$ (Brasil, 2007a), o que reforça a importância dada à atividade de IC pelo órgão. Marcuschi (1996) considera os anos 70 e 80 como o período de "instalação e fortalecimento da pesquisa e da pós-graduação", e os anos 90, período no qual observamos um crescimento significativo no número de bolsas, como a fase da "valorização" da IC, definida por Martins e Martins (I 999) como o "Período da IC".

As bolsas de IC por demanda espontânea ou balcão só podiam ser distribuídas mediante solicitação direta do pesquisador. Os pedidos eram julgados por Comitês Assessores e concedidos por cotas aos pesquisadores, que escolhiam os bolsistas. Em 1988 o CNPq criou o Programa Institucional de Bolsas de Iniciação Científica - Pibic -, um instrumento adicional de fomento, pelo qual bolsas de IC passaram a ser concedidas diretamente às Instituições de Ensino Superior - IES - e aos Institutos de Pesquisa - IPq -, responsáveis por gerenciar diretamente as concessões dessas bolsas. As IES e os IPq têm sob seu controle administrativo as cotas e devem criar dispositivos próprios 
de distribuição, bem como promover anualmente "uma reunião, na forma de seminário ou congresso, onde os bolsistas deverão apresentar sua produção científica sob a forma de pôsteres, resumos e/ou apresentações orais", tendo seu desempenho avaliado pelo Comitê Institucional do Pibic (Brasil, 2007).

Até o momento, o CNPq já realizou duas avaliações sobre o Pibic, "visando obter informações que subsidiassem a definição de parâmetros para um planejamento mais detalhado do programa", como afirma Neder (200I, p.33): uma avaliação qualitativa (Marcuschi, 1996) e outra quantitativa (Aragón, Martins, Velloso, 1999). Os resultados dessas pesquisas indicam que os bolsistas são predominantemente do sexo feminino (51\%), têm idade média de 23,6 anos; os das áreas de Ciências Humanas são os mais velhos, e os últimos a se tornarem bolsistas, enquanto os das Engenharias são os mais jovens e os primeiros bolsistas, sendo que os bolsistas levam em média I,9 ano entre seu ingresso na universidade e seu ingresso no Pibic.

Apesar do aumento considerável na quantidade de bolsas de IC nos últimos anos, o CNPq reconhece que o número de concessões "é exíguo diante da capacidade instalada de orientação no país e do número de alunos de $3^{\circ}$ grau que já atinge mais de 1,6 milhões ao todo" (Marcuschi, apud Neder, 200 I , p. 79). Outro aspecto relevante é a distribuição heterogênea das bolsas por regiões do Brasil: 47,5\% distribuídas no Sudeste, 21,6\% no Nordeste, 17,8\% no Sul, 8, I\% no Centro-Oeste e apenas 5\% no Norte (Neder, 2001 ). De 1989 a 2000, houve um decréscimo no número de bolsas nas regiões Norte, Centro-Oeste e Sul, e um incremento significativo na região Sudeste. Neder (200I) defende que essa heterogeneidade só representa a capacidade de orientação das regiões e destaca a relação entre esses dados e o número de instituições envolvidas no programa em 2000.

A pequena abrangência do programa é uma crítica constante à $\mathrm{IC}$, pois isso restringe a atividade aos "melhores alunos". Bridi (2004, p. 79) constatou, por meio de entrevistas com professores da Universidade Estadual de Campinas - Unicamp -, que as limitações no número de bolsas fazem da IC uma atividade "seletiva, que beneficia poucos e discrimina muitos, aparentemente privilegiando os mais 'capacitados' e 'promissores'”. Outra crítica recorrente ao modelo de IC proposto pelo CNPq, e aplicado na maioria das universidades, é que, além das restrições impostas aos alunos, algumas IES, principalmente as privadas, também são excluídas do processo. Bazin (1983) defende que as 
bases históricas do estabelecimento da IC nas universidades, definida como atividade "selecionada" e "elitizada", contribuíram para limitá-la, "na prática, às universidades onde há pesquisa".

Nas Instituições de Ensino Superior Privadas - lesp -, poucos professores se dedicam à pesquisa - pela característica da universidade e do regime de trabalho - e, consequentemente, o número de alunos envolvidos em IC é muito pequeno. Apesar desse quadro, a atividade de IC não está totalmente excluída das lesp. Em 2006, 1880 bolsas do Pibic foram concedidas a essas instituições, o equivalente a 10,5\% do total. Merece destaque a atuação das Pontifícias Universidades Católicas - PUCs -, que receberam o maior número de bolsas dentre todas as lesp, 34,3\% do total (Brasil, 2007b).

\section{PESQUISAS SOBRE INICIAÇÃO CIENTÍFICA NO BRASIL}

Nosso levantamento bibliográfico indica que poucas pesquisas sobre a atividade de IC foram realizadas no país. De fato, há aproximadamente uma década, Marcuschi ( 1996) já chamava a atenção para esse quadro e afirmava que "pouquíssimas foram as instituições que já fizeram algum tipo de sondagem entre os bolsistas para saber o que eles pensam do programa". Desde então, o quadro permanece praticamente inalterado.

Sobre a temática em questão, foram localizadas seis teses de doutorado, I I dissertações de mestrado e quatro artigos completos publicados em revistas nacionais. A leitura desse conjunto de documentos nos permitiu localizar ainda outros seis trabalhos dispersos em outras revistas, tais como Ciência e Cultura, Biológico, Integração Ensino-Pesquisa-Extensão, Estudos e Debates, Educação Brasileira, Brasília e História, Ciências e Saúde, além de alguns trabalhos apresentados em eventos da Associação Nacional de Política e Administração da Educação - Anpae - e Associação Nacional de Pós-Graduação e Pesquisa em Educação - Anped.

A maior parte dos trabalhos foi publicada na forma de dissertação ou tese, provenientes de diferentes instituições dos vários estados do país. Alguns trabalhos se relacionavam a mais de um curso, ou não determinavam os cursos pesquisados, pois pretendiam obter como resultado um perfil geral da IES. Em alguns casos o trabalho se baseava na análise de documentos disponibilizados pelo CNPq, sem especificação de curso. Em apenas dois trabalhos 
a instituição investigada não coincidia com aquela onde foi defendido o trabalho de pós-graduação.

As teses e dissertações sobre IC encontradas foram produzidas entre 1990 e 2004, sendo a maioria posterior a 2000. Grande parte dos trabalhos sobre IC foi desenvolvida na Unicamp (Bariani, I998; Melo, 2003; Fior, 2003; Bridi, 2004), na Universidade de Brasília (Neder, 2001 ; Carvalho, 2002) e na Universidade Federal de Santa Maria (Oaigen, 1990, 1995). De maneira geral, os cursos de graduação investigados localizam-se na região Sudeste (58,8\%), Sul (23,5\%) e Centro-Oeste ( I I,8\%), e apenas um na região Nordeste (5,9\%). A maioria pertence a instituições públicas, sendo apenas quatro particulares (23,5\%). Os cursos de Humanas foram os mais investigados (35,3\%), seguidos dos cursos da área de Ciências Biológicas $(17,6 \%)$ e de Exatas ( $11,8 \%)$. O curso de Psicologia focalizou três investigações distintas, sendo, portanto, o mais investigado (Bettoi, 1995; Bariani, 1998; Breglia, 2002). A lista completa de artigos, publicados nos periódicos mencionados, está em ordem cronológica no quadro I.

\section{QUADRO I}

ARTIGOS PUBLICADOS SOBRE INICIAÇÃO CIENTÍFICA NO BRASIL

\begin{tabular}{|c|c|}
\hline Autor e Título & Publicação e Ano \\
\hline BAZIN, M. J. O que é a iniciação cientí ca & $\begin{array}{l}\text { Revista de Ensino de Física, v.5, n. I , p.81-88, } \\
\text { I983 }\end{array}$ \\
\hline $\begin{array}{l}\text { ZAKON, A. Qualidades desejáveis na iniciação } \\
\text { cientí ca }\end{array}$ & $\begin{array}{l}\text { Ciência e Cultura, v.4I, n.9, p.868-877, } \\
1989\end{array}$ \\
\hline $\begin{array}{l}\text { CAMPOS, L. F. L.; MARTINEZ, A.; ESCUDERO, } \\
\text { R. M. P. Perspectivas de alunos sobre sua iniciação } \\
\text { cientí ca }\end{array}$ & $\begin{array}{l}\text { Integração Ensino-Pesquisa-Extensão, v.4, } \\
\text { n. |4, p.| 179-182, } 1998\end{array}$ \\
\hline $\begin{array}{l}\text { SILVA, R. C.; CABRERO, R. C. Iniciação cientí ca: } \\
\text { rumo à pós-graduação }\end{array}$ & $\begin{array}{l}\text { Educação Brasileira, v.20, n.40, p. } 189 \text {-199, } \\
1998\end{array}$ \\
\hline $\begin{array}{l}\text { MARTINS, R. C. R.; MARTINS, C. B. } \\
\text { Programas de melhoria e inovação no ensino } \\
\text { de graduação }\end{array}$ & Estudos e Debates, v.20, p. I89-221, 1999 \\
\hline $\begin{array}{l}\text { QUEIROZ, S. L.; ALMEIDA, M. J. P. M. Do fazer } \\
\text { ao compreender ciências: reflexões sobre o apren- } \\
\text { dizado de alunos de iniciação cientí ca em química }\end{array}$ & Ciência e Educação, v. 10, n. I, p.4I-53, 2004 \\
\hline $\begin{array}{l}\text { BECCENERI, J. C.; KIENBAUM, G. S. A iniciação } \\
\text { cientí ca e o programa espacial brasileiro }\end{array}$ & $\begin{array}{l}\text { Integração Ensino-Pesquisa-Extensão, n.47, p. } \\
\text { 377-385, } 2006\end{array}$ \\
\hline
\end{tabular}


No que diz respeito aos trabalhos investigados, além das suas contribuições para a compreensão da atividade de IC no país, que serão discutidas a seguir, é também importante mencionar a metodologia de coleta de dados empregada na maioria deles: questionários realizados com alunos bolsistas de IC, alunos de graduação não bolsistas, ex-bolsistas formados e professores orientadores. Outro instrumento semelhante ao questionário, e também bastante empregado, foi a entrevista, semiestruturada ou aberta, geralmente realizada com sujeitos pré-selecionados na etapa de aplicação dos questionários.

\section{CONTRIBUIÇÕES DAS PESQUISAS SOBRE INICIAÇÃO CIENTIÍFICA NO BRASIL}

A análise dos trabalhos investigados permitiu classificá-los, com relação às suas contribuições para a compreensão da atividade de IC, em três segmentos distintos, que serão discutidos adiante:

- Avaliação da IC como atividade de formação do universitário;

- Avaliação do Pibic com relação aos objetivos almejados pelo programa;

- Caracterização de algumas particularidades do desenvolvimento da atividade de IC.

\section{Avaliação da IC como atividade de formação do universitário}

O rompimento da dicotomia, historicamente existente no ensino superior brasileiro, entre teoria e prática, ensino e pesquisa, e graduação e pósgraduação, tem sido discutido há bastante tempo por diversos pesquisadores (Demo, 1997; Peixoto, 1992). A dificuldade de relacionar ensino e pesquisa na graduação remonta ao fato de que alguns professores estabelecem uma diferença entre a sala de aula e o espaço da pesquisa. Assim, a graduação continua sendo um espaço de reprodução e não de produção de conhecimentos, enquanto o espaço da pesquisa é muito mais valorizado e altera o comportamento dos professores na elaboração das rotinas, na relação com os alunos, no investimento feito. Nessa perspectiva a criação da IC nas universidades surgiu como possibilidade de aproximar e fortalecer as relações entre ensino 
e pesquisa, teoria e prática e graduação e pós-graduação (Bernardi, 2003; Caberlon, 2003; Damasceno, 1999; Alma, 2003). A integração entre ensino e pesquisa promovida pela IC é efetiva, pois permite a

...construção de uma via de mão dupla entre ensino e pesquisa, vai além de estabelecer entre eles uma relação de interdependência: também aporta um novo significado ao ensino de graduação, ao visualizar a sala de aula como mais um espaço de construção do conhecimento. (Breglia, 2002, p.64)

Dessa forma a IC representa "um excelente instrumento educativo que caminha entre a pesquisa e o ensino" (Bridi, 2004). Essa associação pode ser visualizada

...através de informações que os alunos trazem de outras disciplinas para a pesquisa, através de informações e levantamentos produzidos pelos bolsistas que são utilizados na disciplina e até alunos compondo amostras para investigações. (Maldonado, 1998, p.87)

Desempenho na graduação

Muitos autores defendem que os bolsistas de IC apresentam melhores coeficientes de rendimento nos seus cursos de graduação (Leitão Filho, 1996; Caberlon, 2003; Aguiar; 1997; Bridi, 2004; Breglia, 2002; Pires, 2002). Isso ocorre porque os alunos de IC desenvolvem novas estratégias de aprendizagem, como consequência da vivência da pesquisa "aprendem a aprender" (Aguiar, 1997). Na perspectiva de Almeida (1996, p.22) "parece claro que a pesquisa científica pode ser um excelente instrumento educativo na medida em que leva os alunos a lidarem com o processo de conhecer e não apenas com o produto desse processo". A partir desse aprendizado eles se sentem motivados a "cumprir a sua principal função que é estudar. A pesquisa dá o sentido de aprender ao estudo. Isso é fato reconhecido por orientadores, professores, bolsistas e alunos" (Pires, 2002, p. I04). Dessa forma a IC promove um "melhor aproveitamento no curso de graduação, que passa a ser mais valorizado" ou "melhor aproveitamento das disciplinas de graduação, ampliando o âmbito das análises e conteúdos de ensino" (Caberlon, 2003). Além disso, 
a IC proporciona a "formação abrangente", "pela possibilidade de aquisição de conhecimentos científicos e específicos" (Bridi, 2004).

Breglia (2002, p.83), por meio de entrevistas com professores-orientadores, percebeu que eles enxergam a IC como "uma atividade que pode motivar o aluno na sala de aula, e the proporcionar uma visão mais ampla do curso, maior base de conhecimentos prévios, bem como desmistificar conceitos e teorias". Essas constatações confirmam os dados analisados por Aguiar ( 1997, p.88), segundo a qual "para muitos alunos, a IC veio de alguma forma diminuir o descontentamento com a estrutura curricular de seu curso de graduação". Suas queixas estão centradas principalmente na estrutura curricular, no excesso de conteúdo e no pouco significado deste em sua apresentação e na predominância de aulas expositivas.

Desenvolvimento pessoal

Com relação ao desenvolvimento pessoal, as pesquisas apontam algumas "qualidades/habilidades" "despertadas" pela prática da pesquisa e "interiorizadas" para futura vida pro ssional, "quer na prestação de serviços ou na academia, principalmente" (Maldonado, 1998), dentre as quais estão o raciocínio/pensamento crítico, autonomia, criatividade, maturidade e responsabilidade (Calazans, 1999). Os autores destacam ainda que a IC favorece a "evolução intelectual do aluno", o "fomento das capacidades interpretativas, analíticas, críticas e contributivas do aluno" (Caberlon, 2003), "induz o bolsista a formar o seu próprio juízo, a tornar-se dono de seu trabalho e construir uma opinião própria" (Pires, 2002, p. 130), e aprimora as "habilidades de liderança, facilidade nos relacionamentos interpessoais, desenvolvimento de valores altruísticos" (Fior, 2003).

O trabalho de Bazin (1983) dá atenção especial ao desenvolvimento da autonomia proporcionado pela IC. Ele acredita que no ensino médio a posição do estudante é "extremamente dependente, obediente", enquanto no ensino superior ocorre uma "ruptura", que consiste em libertar os estudantes da atitude de perguntar ao professor "é isso que o senhor quer?" para chamá-lo na sala e contar "olha o que eu encontrei, o que eu descobri".

Pires (2002, p. 117 ) percebeu na cultura universitária que o "programa de IC acaba por se tornar um símbolo de status que vai atrair um número cada vez maior de alunos/candidatos". Esse status revela-se nas entrevistas 
realizadas pela pesquisadora por meio de expressões como "ser considerado bom naquilo que faz" e "fazer as pessoas te verem de forma diferente", o que sugere que essa atividade promove a autovalorização e autoestima do bolsista, "reconhecida por ele, no olhar do outro, projetada no outro".

Nova visão da ciência

Alguns autores indicam que a IC possibilita a compreensão do "fazer ciência", pela quebra do mito do ato de pesquisar, da compreensão do papel do cientista, da participação na construção do conhecimento científico, da apreciação pelo pesquisar - satisfação na produção do trabalho de pesquisa e construção de sentidos quanto ao que é a pesquisa.

Dentre os trabalhos que deram maior atenção a essa contribuição da IC, destacamos o de Queiroz e Almeida (2004) e o de Aguiar ( 1997). O primeiro realizou uma pesquisa qualitativa do tipo etnográfica com bolsistas de IC em laboratório de química e concluíram que:

...a "imersão" das alunas no laboratório de pesquisa, que permitiu torná-las aculturadas "à vida de laboratório", trouxe grandes benefícios para a formação de cada uma delas à medida que as tirou da mesmice de concluir um curso de química sem ter a real noção de como se faz química, sem ter a chance de questionar conceitos tão arraigados na sociedade sobre o papel de cientista e de como se faz ciência. (Queiroz, Almeida, 2004, p. 53)

Aguiar (1997, p.94) questionou bolsistas de IC a respeito das suas concepções sobre a ciência e os cientistas: 65,5\% disseram que desconheciam o ambiente da ciência antes da IC, e "alguns consideraram suas concepções anteriores sobre ciência distorcidas mas, posteriormente, modificadas com o maior contato com a ciência através da IC" (34,5\% dos entrevistados).

Socialização profissional

Aguiar percebeu que, quando perguntados sobre sua produção científica, os alunos de IC não se limitaram a declarar o número de trabalhos 
produzidos e apresentados, demonstrando satisfação de concretizar essa etapa da atividade científica.

O estudante tem prazer em ver seu trabalho publicado e apresentado aos seus colegas de IC, pós-graduandos e professores. Esse seria um caminho de socialização profissional, pois começa a ser reconhecido, considerado pelos colegas e membros do laboratório e departamento a que pertencem. (1997, p.99)

A socialização profissional representa "a experiência do contato direto com seu orientador, pós-graduandos e outros graduandos com suas experiências profissionais diversas". Nesse contexto, a aproximação do professor com o aluno é discutida por muitos autores como extremamente benéfica para ambas as partes, uma vez que esse contato não se restringe apenas a discutir aspectos do projeto desenvolvido, o relacionamento próximo com o orientador contribui para a troca de informações e experiências pessoais.

Além do orientador, a convivência com as outras pessoas do grupo também contribui para a socialização pro ssional e favorece o bom desenvolvimento das atividades de IC. Em pesquisa com estudantes de Ciências Biológicas da Universidade Federal do Rio de Janeiro -UFRJ -, Aguiar (1997, p.72) descobriu que "a orientação dos estudantes é também compartilhada com os demais membros do laboratório, aí incluídos professores associados e pós-graduandos". Esse processo foi denominado pela autora como "orientação em cascata", "o chefe do laboratório e o professor associado orientam os pós-graduandos, e estes, os estudantes de iniciação cientí ca"; apesar de o chefe do laboratório compartilhar a orientação dos estudantes de IC, ele continua responsável por ela.

\section{Avaliação do Pibic com relação aos objetivos almejados pelo programa}

No âmbito do CNPq, como agência de fomento à pesquisa no Brasil, fica bastante claro que o objetivo da IC é

....despertar a vocação cientí ca e incentivar talentos potenciais entre estudantes de graduação, mediante sua participação em projetos de pesquisa, preparando-os para o ingresso na pós-graduação; contribuir de forma decisiva para reduzir o tempo médio de titulação de mestres e doutores. (Silva, Cabrero, 1998, p. 193, grifo nosso) 
Esse objetivo transparece, entre outros espaços, nos documentos de avaliação produzidos pelo CNPq, na tentativa de verificar o destino dos exbolsistas, o tempo para o ingresso e conclusão da pós-graduação. Cabrero, Costa e Hayashi (2006, p.6) comparam a "trajetória de mestrandos e doutorandos" dos EUA, que concluem o doutorado entre 28 anos e 32 anos, com a dos brasileiros que, em 1995, "estavam defendendo as teses, em média, com 40 anos", e destacam a necessidade de alterar esse aspecto na pós-graduação brasileira, "um mecanismo que muito contribuiu para alterar o quadro apresentado foi a concessão de bolsas de Iniciação Científica". Consta do Informativo do Pibic que

...no sentido de contribuir para que este tempo de titulação de mestres e doutores seja reduzido, o CNPq vem investindo de forma maciça, desde a década de 50, em iniciação científica, despertando no jovem universitário uma nova mentalidade em relação à pesquisa, propiciando-lhe aprendizagem de novas técnicas e métodos científicos. (apud Cabrero, Costa, Hayashi, 2006, p.6-7)

Neder (200 I), em extensa avaliação da IC como ação de fomento do CNPq, acredita que "o Pibic vem mostrando a eficácia da IC sobre a formação do futuro pesquisador" e "o poder incentivador que exerce sobre as IES na ampliação e consolidação de núcleos de pesquisa”. Esses dados são confirmados pela pesquisa de Aragón, Martins e Velloso (I 999), encomendada pelo CNPq, na qual foi possível revelar que um ex-aluno bolsista do Pibic tem seis vezes mais chance de iniciar uma pós-graduação do que um graduado não bolsista. Isso porque "3 em cada 10 bolsistas Pibic chegam ao mestrado [...] o prazo médio de transição entre a conclusão da graduação e o ingresso no mestrado, para um ex-bolsista Pibic, é de I,2 ano", enquanto para os não bolsistas chega a 6,8 anos em média (Aragón, Martins, Velloso, 1999, p.34, 36).

Além dos dados do CNPq, é também digno de nota o trabalho de Cabrero, Costa e Hayashi (2003), resultado de pesquisa realizada na Universidade Federal de São Carlos. Esse trabalho mostra que aproximadamente $60 \%$ dos egressos do Pibic se dirigem para o mestrado na própria instituição e que, "em termos de pesquisas preliminares, acredita-se que mais de 40\% dos egressos do Pibic/UFSCar, que finalizaram a bolsa entre 1994 e 1998 , 
defenderam a dissertação de mestrado e/ou tese de doutorado" (Cabrero, Costa, Hayashi, 2003, p. I0).

Maccariello, Novicki e Castro (1999) investigaram a IC na Universidade Estadual do Rio de Janeiro - Uerj - e destacaram o número de ex-bolsistas de IC que ingressaram em programas de pós-graduação como um indicador do sucesso alcançado pelo Pibic. Segundo eles, um levantamento preliminar (1997/1998) verificou que 22\% dos estudantes graduados pela Uerj que ingressaram em programas de pós-graduação da Uerj foram detentores de bolsas de IC.

Camino e Camino também divulgaram dados animadores sobre os resultados do Pibic e das bolsas por demanda espontânea (balcão) na Universidade Federal da Paraíba, que tiveram início em 1988. Comparando os anos de 1985 e 1993, os autores observaram um decréscimo na idade de ingresso do mestrado de 30,6 para 28,4; a porcentagem de teses defendidas aumentou de $20 \%$ para $87,5 \%$; e a duração do mestrado diminuiu de 3 para 2,5 anos. Além disso, a média da publicação discente é de I por aluno e a de participação em congresso é de 2 por aluno; os autores justificam esses índices pelo fato de que "boa parte dos atuais alunos começam a divulgar o que produziram enquanto bolsistas de IC". E destacam que

...se, por um lado, os alunos estão ingressando no mestrado bem mais jovens e praticamente recém-graduados, por outro lado, graças à experiência obtida durante a bolsa nas atividades de pesquisa, estes jovens estão se mostrando mais produtivos e garantindo a defesa da dissertação em menor tempo. (1996, p.5।)

É inegável que a IC encaminha o bolsista para a vida acadêmica e permite, de maneira única, vivenciar essa possível opção de atuação profissional, antes mesmo de ele estar formado. De modo geral, as contribuições da IC para a formação do pesquisador se refletem no encaminhamento do aluno para a pós-graduação e na agregação de qualidade aos cursos de pós-graduação. Guimarães (1992, p.29) defende essa ideia afirmando que os bolsistas "que seguirem para a pós-graduação vão compensar isto largamente na redução do tempo médio de titulação, na menor taxa de evasão, na eliminação do mestrado como etapa obrigatória para o doutorado, além de sensível melhora 
qualitativa do trabalho experimental". Leitão Filho justifica a "economia de tempo" propiciada pela IC

...em função do treinamento anterior que Ihes deu familiaridade com técnicas básicas de consulta bibliográ ca, metodologia cientí ca, uso de equipamentos de laboratório e informática, maior fluência em leitura em língua estrangeira. Além destas vantagens, normalmente bolsistas de IC já estão familiarizados e envolvidos no projeto de tese, o que representa um avanço nada desprezível. (1996, p.21)

Segundo Campos, Martinez e Escudero (1998), 53, $13 \%$ dos alunos "enxergam a IC como uma oportunidade para iniciar a carreira de pesquisador". Bridi (2004, p.7l), por meio de questionários distribuídos entre docentes, identificou que " $42,8 \%$ revelam o entendimento que a maior contribuição da IC se dá em relação ao ensino de pós-graduação, em termos, tanto de 'encaminhamento/ingresso' como de 'facilitação/agilização' de seu desenvolvimento". Neder (200 I), em análise dos resultados sobre IC publicados pelo CNPq, observou que, entre os bolsistas entrevistados, quase $100 \%$ consideraram importante ou muito importante participarem do Pibic, "visto como 'instrumento' para o exercício profissional no meio acadêmico", e para mais de $50 \%$ dos entrevistados "a participação no Pibic representou a oportunidade de introduzir-se em atividades de pesquisa". Pesquisadores entrevistados por Oaigen (1 995) citam a participação em atividades de IC como um dos "aspectos facilitadores para a formação como pesquisador" (p. I | 6), e "momentos importantes em sua vida de estudante que marcaram a sua de nição pelo exercício da pesquisa como pro ssional" (p. I3I). Segundo Breglia (2002), 76,9\% dos entrevistados preferiram a resposta afirmativa quando questionados sobre a influência da IC na opção pela atividade profissional. Pires determinou que a IC contribui para que a perspectiva do aluno, em dar continuidade a sua formação após a conclusão da graduação, seja alcançada, porque:

...representa um instrumento de tomada de decisão do bolsista, ajudando-o a definir um rumo e a criar estratégias, no vasto e diversificado currículo dos cursos da graduação; possibilita ao bolsista ter o exemplo do orientador como referência para a construção de seu futuro profissional, induzindo-o ao ingresso direto no mestrado ou até mesmo no doutorado; cria no bolsista a percepção 
de que tem maior probabilidade que os demais em concretizar o projeto após o curso, tornando-se mais competitivo; os alunos não bolsistas também fazem planos de ingressar numa pós, mas muitos deles não sabem, ainda, como fazer ou por que fazer um mestrado; permite ao bolsista o diálogo entre áreas diferentes, a do curso e a do projeto, abrindo-se um leque de possibilidades de formação para o exercício futuro de qualquer profissão. (2002, p. I 3 I)

Camino e Camino (1996, p.62), por meio de entrevistas com alunos de graduação bolsistas e não bolsistas e alunos de mestrado, perceberam que "o perfil do aluno de graduação, bolsista de IC, é semelhante ao do aluno do mestrado. Esta semelhança parece indicar que as mudanças de atitude são determinadas não pelo nível da formação, mas pela prática de pesquisa". Como resultado de sua análise, Carvalho (2002) indica que "o contato com as atividades de pesquisa e o relacionamento com o orientador envolvem os bolsistas na lógica de funcionamento do campo científico, conduzindo-os ao interesse pela continuidade na carreira acadêmica". Os dados também sugerem que o interesse de seguir a carreira científica tende a ser maior para os bolsistas que participam de pesquisas desenvolvidas pelos orientadores, indicando que a melhor compreensão do campo científico, suas regras e seus possíves "lucros simbólicos" favorece o interesse pela área, ou seja,

... a participação em uma pesquisa já consolidada parece levar a uma melhor compreensão das diversas possibilidades do campo científico, tais como o alcance de resultados satisfatórios, oportunidades de publicação, participação em eventos, reconhecimento social, entre outras. (Carvalho, 2002, p. I52)

Apesar de o encaminhamento para a pós-graduação ser um dos principais objetivos da IC, e consequentemente ser a principal contribuição dessa atividade apontada pelas pesquisas, muitos autores destacam também a contribuição da IC para a atuação profissional dos bolsistas fora do ambiente da pesquisa. Em entrevista com professores-orientadores, Breglia (2002) percebeu que para eles "a vivência da pesquisa é um diferencial para o que chamam de "mercado de trabalho'" e destaca que nessa perspectiva a IC "é vista pelos professores como uma possibilidade de trabalho e aprendizado sem o clima competitivo e de pressão constante de um estágio". 
Maldonado (1998, p. I I 8) aponta o encaminhamento "precoce" dos profissionais, ex-bolsistas, para os cursos de pós-graduação como a principal contribuição da atividade de IC. Para ela "a principal contribuição está na sensibilização para a pesquisa com todos os subprodutos envolvidos, como desenvolvimento da capacidade de argumentação, de abstração, de criação de problemas, do raciocínio crítico, ou seja, o desenvolvimento do habitus científico". Assim, a IC contribui também para a prática profissional daqueles alunos que não prosseguem na carreira acadêmica.

\section{Caracterização de algumas particularidades do desenvolvimento da atividade de IC}

Apesar de os programas o ciais trazerem as principais diretrizes para o desenvolvimento da IC nas universidades, existem algumas diferenças na maneira pela qual essas diretrizes são seguidas - pelo menos nas IES que foram alvo de investigação nos últimos anos e que tiveram algumas características dos seus programas de IC divulgadas em dissertações, teses e artigos cientí cos. Essas diferenças revelam que, apesar de seguir os procedimentos o ciais, o desenvolvimento do trabalho é determinado principalmente, ou quase exclusivamente, pelo orientador, o que de ne diferentes formas de condução da pesquisa com relação ao tipo de atividade, seleção do bolsista, di culdades encontradas, entre outras.

Nem sempre os bolsistas vivenciam todas as etapas da realização de uma pesquisa científica, que compreende o levantamento bibliográfico, a elaboração do projeto de pesquisa, a realização de experimentos visando à coleta de dados, a análise e a discussão dos resultados etc. Caberlon (2003) estimou a porcentagem de participação dos bolsistas nas diferentes etapas da pesquisa científica e apontou a existência de uma concentração dos alunos de IC em atividades como "revisão bibliográfica", "coleta de dados" e "tabulação de dados". Poucos são aqueles que participam da elaboração do "referencial teórico" e da "sistematização e avaliação de resultados".

Além disso, Simão et al. (1996) reconheceram dois "modelos" de inserção do aluno na pesquisa desenvolvida pelo grupo coordenado pelo orientador: o "projeto individual" e o "projeto integrado". No "projeto individual", professor e aluno iniciam a discussão de um problema de pesquisa e, a partir daí, o aluno participa de todas as etapas da elaboração de um projeto de pesquisa. 
No "projeto integrado", o aluno se engaja em algum projeto já existente no grupo de pesquisa do professor, vindo a desenvolver efetivamente partes de uma pesquisa em andamento, tendo, entretanto, acesso ao conhecimento do todo. Os autores destacaram que, "em alguns casos, o aluno se engaja inicialmente num projeto integrado e, posteriormente, com base em questões oriundas, passa a desenvolver um projeto individual" (Simão et al., 1996, p. I |2). Frequentemente a inserção inicial em um "projeto integrado" serve como forma de verificar a intenção e a persistência do aluno na realização da pesquisa; posteriormente, a solicitação da bolsa para esse aluno é feita para um "projeto individual". Carvalho (2002) também investigou a questão e, pelos dados da pesquisa conduzida pelo Núcleo de Pesquisa sobre Ensino Superior da Universidade de Brasília - Nesub/UnB -, constatou que 51,9\% dos projetos de pesquisa da IC eram parte integrante de pesquisa maior do orientador, 35, I \% eram projetos individuais vinculados à pesquisa do orientador e apenas 13\% eram individuais e não estavam vinculados a uma pesquisa do orientador.

\section{Motivação para a pesquisa}

Campos, Martinez e Escudero (1998), por meio de entrevistas com 28 universitários de uma lesp do Estado de São Paulo matriculados em programas de IC não governamentais, perceberam que, de maneira geral, os bolsistas se sentem muito motivados para participar da IC (68\%) e apontam muita (36\%) e extrema (50\%) necessidade de pesquisas e produção de conhecimento para a sua área de estudo. Aguiar ( 1997) investigou alunos de IC da Universidade Federal do Rio de Janeiro, matriculados em cursos da área de Ciências Biológicas, e os resultados confirmam os altos índices de motivação encontrados por Campos, Martinez e Escudero (1998). Segundo a autora, "70, I \% dos alunos procurou a IC por iniciativa própria e um percentual menor foi convidado por um professor (29,9\%) ou membro do laboratório" (Aguiar, 1997, p.63).

Outros autores investigaram os possíveis motivos que levam os alunos a participar de programas de IC: a "complementação do ensino de graduação", por meio da "busca/ampliação de conhecimentos" (Caberlon, 2003); o desenvolvimento de "habilidades na área do curso de graduação"; "investimento na sua formação de graduação" (Pires, 2002); e a possibilidade de "convívio com 
pesquisadores em ambiente familiar" (Maccariello, Novicki, Castro, 1999). Também uma "certa insatisfação com a relação linear da sala de aula na transmissão de conhecimentos" foi mencionada (Maldonado, 1998) e a busca do "conhecer o que é pesquisa" (Caberlon, 2003) e "iniciar o caminho para a pós-graduação" (Aguiar, 1997). Com menor incidência, aparecem a importância da atividade "para o curriculum vitae" (Aguiar, 1997); a "possibilidade de contribuição à sociedade" (Caberlon, 2003); e a "formação da postura profissional" (Maldonado, 1998).

Pires (2002) ressaltou que somente $2 \%$ dos alunos entrevistados em sua pesquisa buscaram a IC "apenas por ser uma fonte de renda". Esse resultado condiz com outras pesquisas que apontam o financiamento como não determinante para a inserção do aluno no projeto.

Seleção do orientando/orientador

Dentre as pesquisas que determinaram critérios de seleção do orientando/orientador, a quantidade de trabalhos centrados nos critérios de seleção do orientador é menor. Pires (2002) percebeu que os orientandos escolhem o orientador "pelo tema da pesquisa $(33,3 \%)$ ou pela linha de pesquisa $(21,6 \%)$ ", apenas 33,3\% disseram ter sido "procurado/convidado pelo orientador". A autora acredita que aí "estão os voluntários, aqueles alunos já engajados no grupo de pesquisa de determinado projeto de um orientador que quando há necessidade de alguma substituição, recruta um desses voluntários" (p.79). $\bigcirc$ único trabalho que investigou os critérios de seleção do orientador foi o de Zakon ( 1989), que questionou tanto os bolsistas quanto os professores sobre o per I desejável do orientador. Os dois grupos coincidiram com relação aos seguintes atributos: ser acessível, sincero e amigo, ser motivador para a pesquisa e conhecer o assunto da pesquisa. Os iniciantes desejam que os orientadores sejam comunicativos e didáticos, e que informem e treinem o aluno sobre a pesquisa. Os orientadores destacam como características do per I desejável do orientador ter interesse no processo de formação do estudante e designar um trabalho/projeto para cada aluno. Zakon (1989) também questionou os orientadores e os bolsistas com relação ao per I desejável do estudante, obtendo como resposta: o interesse pelo trabalho desenvolvido, responsabilidade e tempo disponível. Os alunos priorizam mais do que os orientadores a iniciativa própria e o saber organizar atividades, 
pensamentos e textos. Por sua vez, os professores indicaram desejar nos alunos vocação para a pesquisa (capacidade de observar, discernir e propor soluções), características intelectuais (curiosidade, vontade de aprender, criatividade, fácil aprendizado, inteligência), dedicação às atividades de iniciação, persistência na pesquisa e capacidade de convivência (comunicar-se, dialogar e participar). Portanto, "ser um aluno bom (com notas acima da média)" não é um aspecto muito valorizado nos depoimentos de ambos os grupos, a despeito do esperado pelos órgãos de fomento à pesquisa.

É interessante perceber que os dados obtidos por Zakon (1989), há vinte anos, com orientadores/orientandos da área de Química e Engenharia Química coincidem plenamente com os resultados obtidos na pesquisa mais recente de Perrelli e Gianotto (2005) com 40 professores de Ciências Biológicas e da Saúde. Segundo eles, na escolha dos iniciantes no campo científico, os professores valorizam competências como a "capacidade de tomar decisões, resolver problemas com autonomia", mas não consideram tão importante o "domínio de conteúdos específicos de sua área de pesquisa".

Simão et al. (1996) determinaram que a seleção de alunos para a IC é feita com base em cursos ministrados pelos professores orientadores na graduação. Muitas vezes "os docentes inclusive ministram seus cursos já com a perspectiva de sugerir possibilidades de pesquisa aos alunos” (p. | |2). Maldonado (1998) percebeu que, em geral, a seleção é realizada mediante entrevistas com os pretendentes. Nestas, os orientadores citaram como critérios: o período letivo do aluno - alguns preferem no início do curso porque têm mais tempo, outros mais tarde, porque já cursaram a disciplina do docente orientador; o coeficiente de rendimento, que costuma ser importante, mas não definitivo; o domínio de língua inglesa e noções de informática. Porém, segundo ela, "o critério mais valorizado é a capacidade de organização do aluno frente às suas tarefas como aluno e como bolsista. As atividades referentes ao curso como provas, seminários, visitas não podem ser obstáculos para o cumprimento das exigências da pesquisa" (p.90).

Expectativas, decepções e dificuldades vivenciadas na Iniciação Científica

Bridi (2004, p.58), em entrevista com 400 alunos da Unicamp, reconheceu que as expectativas desses quanto à participação na pesquisa durante 
a graduação se deram em relação a "uma boa formação (42,2\%)", "direcionamento profissional ( $12,1 \%)$ ", "uma boa orientação $(6,8 \%)$ ", e "reconhecimento do trabalho $(5,4 \%)$ ". Com relação aos orientadores, a maioria dos estudantes $(67,1 \%)$ mencionou a "busca por uma orientação pessoal direta, que os auxiliasse na construção e desenvolvimento do projeto de pesquisa". Essas expectativas foram totalmente atendidas para $61,5 \%$ dos alunos respondentes; parcialmente atendidas para 34,6\% dos estudantes e não atendidas para apenas $3,8 \%$ dos orientandos. A frustração com os orientadores, embora tenha uma porcentagem baixa, está ligada à falta de tempo e ao excesso de atividades do orientador (27,8\%). No entanto, alguns alunos sentiram que seus orientadores se mantiveram distantes das suas atividades de orientação $(6,3 \%)$ ou que tinham pouco interesse no tema (3,8\%).

De modo geral, 53,8\% dos entrevistados experimentaram algum nível de decepção durante o período de desenvolvimento do programa. A decepção com o orientador foi a categoria que apareceu com maior frequência, resultante, para 17,7\% dos alunos, do pouco contato com o orientador, mas também há decepções com o próprio andamento do trabalho (10,1\%). Alguns alunos se decepcionaram com a falta de aplicação dos resultados obtidos, com a pouca valorização e utilidade do material produzido (8,9\%), mencionando a falta de extensão de suas atividades de pesquisa descrita como uma das finalidades das universidades (ensino, pesquisa e extensão). Em menor porcentagem, foram mencionados aspectos que se referem à decepção com o sistema burocrático (7,6\%), com o valor da bolsa (6,3\%), com a falta de estrutura de laboratórios e materiais necessários à pesquisa (6,3\%) e decepções individuais (2,5\%).

Segundo Campos, Martinez e Escudero (1998) e Bridi (2004), por sua vez, as principais dificuldades da IC são "falta de tempo para a IC e excesso de atividades", "falta de conhecimento necessário para a IC" e "falta de orientação/contato com o orientador". Outra dificuldade bastante frequente, mencionada por 32,9\% dos bolsistas entrevistados (Bridi, 2004, p.66), se refere ao andamento do projeto: "os alunos queixaram-se da dificuldade na redação dos relatórios, na escolha da bibliografia, na escolha do método de pesquisa, nos erros ocorridos nos experimentos e na complexidade das análises de dados". Em instituições privadas ou com pouca tradição em pesquisa os alunos enfrentam ainda outros tipos de problemas. Alma (2003) descreve alguns pontos negativos da pesquisa de IC conduzida numa lesp, identificados 
por meio de entrevistas com os alunos: "custo dos experimentos", "falta de apoio financeiro para a pesquisa" e "pessoal técnico e de apoio pouco treinado para orientá-los".

\section{CONSIDERAÇÕES FINAIS}

Este artigo evidenciou a natureza e discutiu as contribuições de pesquisas sobre IC realizadas no Brasil, de 1983 ao primeiro semestre de 2007, para o entendimento dessa atividade. A análise do conjunto de pesquisas apontou para a existência de um amplo consenso sobre o papel relevante que a IC desempenha na formação dos graduandos, principalmente no que diz respeito às atividades realizadas no curso de graduação, ao desenvolvimento pessoal, à construção de uma nova visão de ciência e à socialização profissional. Existe, da mesma forma, um consenso sobre os importantes objetivos alcançados pelos programas de fomento à $\mathrm{IC}$, particularmente o Pibic, tendo em vista que despertam e incentivam a vocação científica dos graduandos, além de favorecer a ampliação e a consolidação de núcleos de pesquisa nas IES.

Apesar da relevância e das importantes contribuições advindas da atividade de IC nas IES, ainda são poucas as investigações realizadas a esse respeito. Nesse contexto, existe uma concentração de investigações em determinadas áreas do conhecimento, como a área de Ciências Humanas, e uma quantidade exígua de trabalhos em áreas como Ciências da Saúde, Ciências Exatas e Tecnológicas. Assim, a análise das pesquisas também aponta para a necessidade de fomento ao desenvolvimento de investigações que venham a contribuir para o preenchimento dessa lacuna, de forma a favorecer o progresso de discus-

sões a respeito da temática. É ainda notável a semelhança entre as questões de pesquisa e as metodologias adotadas para coleta e análise dos dados em vários trabalhos, o que sugere a necessidade de diversificação desses procedimentos, que pode resultar em contribuições importantes para esse campo de pesquisa.

\section{REFERÊNCIAS BIBLIOGRÁFICAS}

AGUIAR, L. C. C. O Perfil da iniciação científica no Instituto de Biofísica Carlos Chagas Filho e no Departamento de Bioquímica Médica da Universidade Federal do Rio de Janeiro. 1997. 
Dissertação (Mestrado em Química Biológica) - Centro de Ciências da Saúde, Instituto de Ciências Biomédicas, Universidade Federal do Rio de Janeiro, Rio de Janeiro.

ALMA, J. M. Iniciação científica e interdisciplinaridade: contribuição ao conhecimento da influência da pesquisa na formação do aluno dos cursos de medicina e enfermagem. 2003. Dissertação (Mestrado em Educação) - Universidade Cidade de São Paulo. São Paulo.

ALMEIDA, L. M. A. C. A Importância do programa de iniciação cientí ca para a formação de pesquisadores. In: ENCONTRO DE INICIAÇÃO CIENTÍFICA DA USF, I. I 996, Bragança Paulista. Anais... Bragança Paulista: Universidade São Francisco/Ippea, 1996. p.22-24.

ARAGÓN, V. A.; MARTINS, C. B.; VELLOSO, J. R. O Programa Institucional de Bolsas de Iniciação Científica: Pibic e sua relação com a formação de cientistas. Brasília: Nesub, UnB, 1999. (Relatório nal).

BARIANI, I. C. D. Estilos cognitivos de universitários e iniciação científica. 1998. Tese (Doutorado em Educação) - Faculdade de Educação, Universidade Estadual de Campinas, Campinas. Campinas.

BAZIN, M. J. O Que é a iniciação cientí ca. Revista de Ensino de Física, São Paulo, v.5, n. I , p.8I-88, jun. 1983.

BERNARDI, M. M. A Importância da iniciação cientí ca e perspectivas de atuação pro ssional. Biológico, São Paulo, v.65, n. I/2, p. 101 , jan./dez.2003.

BETTOI, S. M. O Pesquisar na graduação: a palavra do aluno de psicologia sobre as condições presentes na sua vida acadêmica. 1995. Dissertação (Mestrado em Psicologia) - Pontifícia Universidade Católica de São Paulo. São Paulo.

BRASIL, Ministério da Ciência e Tecnologia. Conselho Nacional de Desenvolvimento Cientí co e Tecnológico. Anexo III da RN-0 17/2006: bolsas por quota no país; Pibic - norma especí ca. 2007. Disponível em: http://www.cnpq.br/normas/rn_06_017_anexo3.htm. Acesso em: 27 jan. 2007.

Estatísticas e indicadores do fomento: quantitativo de bolsas. Versão em excel. 2007a. Disponível em: http://www.cnpq.br/estatisticas/docs/zip/bolsas.zip. Acesso em: 5 jan. 2007.

Programas especiais: Pibic, quota 2006/2007. 2007b Disponível em: http:// www.cnpq.br/programasespeciais/pibic/quota06-07.htm. Acesso em: 5 jan. 2007.

BREGLIA, V. L. A. A Formação na graduação: contribuições, impactos e repercussões do PIBIC. 2002. Tese (Doutorado em Educação) - Pontifícia Universidade Católica do Rio de Janeiro, Rio de Janeiro. 
BRIDI, J. C. A. A Iniciação científica na formação do universitário. 2004. Dissertação (Mestrado em Educação) - Faculdade de Educação, Universidade Estadual de Campinas, Campinas.

CABERLON, V. I. Pesquisa e graduação na Furg: em busca de compreensões sob distintos horizontes. 2003. Tese (Doutorado em Educação) - Faculdade de Educação, Universidade Federal do Rio Grande do Sul, Porto Alegre.

CABRERO, R. C.; COSTA, M. P. R.; HAYASHI, M. C. P. I. Estudantes do ensino superior vivenciando ciência: efeitos na pós-graduação. In: SEMINÁRIO ESTADUAL DAASSOCIAÇÃO NACIONAL DE POLÍTICA E ADMINISTRAÇÃO DE EDUCAÇÃO, 10. 2006. SBC. Anais... São Bernardo do Campo: Universidade Metodista de São Paulo, 2006. v. I . p. I - 10.

A Influência da pesquisa na graduação e do programa de pós-graduação em educação especial, no âmbito da Universidade Federal de São Carlos, para a formação de docentes. In: SEMINÁRIO INTERNACIONAL DE EDUCAÇÃO: TEORIAS E POLÍTICAS, 2003. São Paulo. Anais... São Paulo: Uninove, 2003. p. I - 12.

CALAZANS, J. Articulação teoria/prática: uma ação formadora. In: CALAZANS, J. (Org.). Iniciação científica: construindo o pensamento crítico. São Paulo: Cortez, 1999. p.57-78.

CAMINO, L.; CAMINO, C. Os Programas de iniciação cientí ca: via de integração entre graduação e pós-graduação. In: SIMPÓSIO DE PESQUISA E INTERCÂMBIO CIENTÍFICO DA ASSOCIAÇÃO NACIONAL DE PESQUISA E PÓS-GRADUAÇÃO EM PSICOLOGIA, 6, 1996. Rio de Janeiro. Anais... Rio de Janeiro: Anppep, 1996. p.46-63.

CAMPOS, L. F. L.; MARTINEZ, A.; ESCUDERO, R. M. P. Perspectivas de alunos sobre sua iniciação cientí ca. Integração Ensino-Pesquisa-Extensão, São Paulo, v.4, n. |4, p.|79-182, ago. 1998.

CARVALHO, A. G. O Pibic e a difusão da carreira científica na universidade brasileira. 2002. Dissertação (Mestrado em Sociologia) - Universidade de Brasília, Brasília.

DEMO, P. Educar pela pesquisa. Campinas: Autores Associados, 1997.

DAMASCENO, M. N. A Formação de novos pesquisadores: a investigação como uma construção coletiva a partir da relação teoria-prática. In: CALAZANS, J. (Org.). Iniciação científica: construindo o pensamento crítico. São Paulo: Cortez, 1999. p. I3-56.

FIOR, C. A. Contribuições das atividades não obrigatórias na formação universitária. 2003. Dissertação (Mestrado em Educação) - Faculdade de Educação, Universidade Estadual de Campinas, Campinas.

GUIMARÃES, J. A. A Iniciação cientí ca e a pesquisa na graduação. In: SEMINÁRIO DE PESQUISA NA GRADUAÇÃO “VOCÊ PESQUISA? ENTÃO MOSTRE!", I, I 992, Brasília. Anais... Brasília: Universidade de Brasília, 1992. p.27-35. 
HOUAISS, A. Dicionário eletrônico da língua portuguesa. Disponível em: http://houaiss.uol. com.br/busca.jhtm. Acesso em: 15 jan. 2007.

LEITÃO FILHO, L. M. A. A Importância do programa de iniciação cientí ca para a formação de pesquisadores. In: ENCONTRO DE INICIAÇÃO CIENTÍFICADA USF, I, I 996. Bragança Paulista. Anais... Bragança Paulista: Universidade São Francisco/lppea, 1996. p.21.

MACCARIELLO, M. C. M. M.; NOVICKI, V.; CASTRO, E. M. N. V. Ação pedagógica na iniciação cientí ca. In: CALAZANS, J. (Org.). Iniciação científica: construindo o pensamento crítico. São Paulo: Cortez, 1999. p.79-। I6.

MALDONADO, L. A. Iniciação científica na graduação em nutrição: autonomia do pensar e do fazer na visão dos pesquisadores/orientadores. 1998. Dissertação (Mestrado em Educação) Faculdade de Educação, Universidade do Estado do Rio de Janeiro, Rio de Janeiro.

MASSI, L. Contribuiç̧ões da iniciação cientí ca na apropriação da linguagem cientí ca por alunos de graduação em Química. 2008. Dissertação (Mestrado) - Instituto de Química da Universidade de São Paulo, São Carlos.

MARCUSCHI, L. A. Avaliação do Programa Institucional de Bolsas de Iniciação Científica (PIBIC) do CNPq e Proposta de Ação. Recife: UFPe, 1996. (Relatório Final). mimeo

MARTINS, R. C. R.; MARTINS, C. B. Programas de melhoria e inovação no ensino de graduação. Estudos e Debates: Uma Política de Ensino Superior, Brasília, v.20, p. I89-221, mar. 1999.

MELO, G. F. A. A Formação inicial e a iniciação científica: investigar e produzir saberes docentes no ensino de álgebra elementar. 2003. Tese (Doutorado em Educação) - Faculdade de Educação, Universidade Estadual de Campinas, Campinas.

NEDER, R. T. A Iniciação científica como ação de fomento do CNPq: o programa institucional de bolsas de iniciação cientí ca - Pibic. 200l. Dissertação (Mestrado em desenvolvimento Sustentável) - Centro de Desenvolvimento Sustentável, Universidade de Brasília, Brasília.

OAIGEN, E. R. A Influência das atividades não-formais e extraclasse na iniciação à educação científica. 1990. Dissertação (Mestrado em Educação) - Faculdade de Educação, Universidade Federal de Santa Maria, Santa Maria.

Atividades extraclasse e não-formais uma política para a formação do pesquisador. 1995. Tese (Doutorado em Educação) - Faculdade de Educação, Universidade Federal de Santa Maria, Santa Maria.

PEIXOTO, M. C. L. Associação ensino-pesquisa na universidade: caminhos para um discurso. Educação e Sociedade, São Paulo, v. 13 , n.4I, p. I26-|40, abr. 1992. 
PERRELLI, M, A. S.; GIANOTTO, D. E. P. Percepções de professores universitários sobre a iniciação cientí ca: uma análise a partir de Pierre Bourdieu e Thomas Kuhn. In: ENCONTRO NACIONAL DE PESQUISA EM ENSINO DE CIÊNCIAS, 5, 2005. Bauru. Atas... Bauru: Associação Brasileira de Pesquisa em Educação em Ciências, 2005. p.345-355.

PIRES, R. C. M. A Contribuição da iniciação científica na formação do aluno de graduação numa universidade estadual. 2002. Dissertação (Mestrado em Educação) - Faculdade de Educação, Universidade Federal da Bahia, Salvador.

QUEIROZ, S. L.; ALMEIDA, M. J. P. M. Do fazer ao compreender ciências: reflexões sobre o aprendizado de alunos de iniciação cientí ca em química. Ciência e Educação, Bauru, v. I O, n. I, p.4I-53, 2004.

SILVA, R. C.; CABRERO, R. C. Iniciação cientí ca: rumo à pós-graduação. Educação Brasileira, Brasilia, v.20, n.40, p.0189-199, $1^{\circ}$ sem. 1998.

SIMÃO, L. M. et al. O Papel da iniciação cientí ca para a formação em pesquisa na pósgraduação. In: SIMPÓSIO DE PESQUISA E INTERCÂMBIO CIENTÍFICO DAASSOCIAÇÃO NACIONAL DE PESQUISA E PÓS-GRADUAÇÃO EM PSICOLOGIA, 6, 1996. Rio de Janeiro. Anais... Rio de Janeiro: Anppep, 1996. p. II I - II 3.

ZAKON, A. Qualidades desejáveis na iniciação cientí ca. Ciência e Cultura, Campinas, v.4I, n.9, p.868-877, set. 1989.

Recebido em: agosto 2007

Aprovado para publicação em: abril 2009 